usually demonstrated as an accumulation of the débris of tissue change, or metamorphosis, and principally found in the form of some not well defined acid, as lithic acid, in excess.

There is in the tonsils we may say, as an offset, anatomically, lymph follicles, fibrous and retiform, and peritonsillar connective tissue, which answer in every respect to the fibrous tissue in the joints, and other portions of the body ; and if we place the anatomical relations of both in the same category, we cannot be otherwise than struck with the similarity of the symptoms, and course in both diseases. So that in this respect also, the parallel may be drawn in a way not inconsistent with their relation.

As regards the therapentics of rheumaticotonsillar inflammation, it would appear that the alkaline treatment is that which is best indicated. The same treatment indeed that is indicated in general acute rheumatism : bicarbonate of potassa, ur soda with Dover's powder, salicylate of potassa, or soda, or salol, internally, with a spray of glyceride of borax and carbolic acid, keeping the bowels open and restricting the nitrogenous diet, with acidulous drinks, is all that is generally required in its management.

The termination of the attack is generally uncertain ; is often protracted, and is very prone to leave a residual complication.

Thus the relation of tonsillitis to rheumatism may be traced pretty clearly by its etiology, its pathology, as well as clinically and anatomically, and also as regards its therapeutics, and in closing this brief sketch, though I am sure very imperfectly, of their relationship, I present the following conclusions as a review of the propositions I have attempted to make :

I. They have probably the same etiological factors.

2. These are not very apparent, but are doubtless represented by some agents, atmospheric in principle.

3. They are equally liable to the same cause.

4. Which may produce one or the other.

5. Their pathology is similar.

6 . Their anatomical elements very nearly related.

7. Their symptoms and course very much alike.

8. Their therapeutics allied in every particular.

The Local Treatment of Syphilitic PheNOMENA.-DR. G. Frank LydSTON, of Chicago, says that the obstinate headaches of both late and early syphilis, whether associated with cranial bone lesions or not, are benefited by frictions of the scalp with hydrarg. oleat., ro per cent. In obstinate cases a blister to the nuchia, followed by mercurial plaster, is quite effective. There are occasional cases of cephalalgia associated with the cachexia syphilitica where the galvanic current is of great service.
REMARKS AND CLINICAL REPORT ON THE USE OF THE WEIGERT HOT AIR INHALING APPARATUS.

Read in the Section of Laryngology and Otology at the Fortieth Annual Meeting of the American Medical Association, June, r889.

BY E. L. SHURLY, M.D., OF DETROIT, MICH.

In presenting the following brief and imperfect report of the "Weigert A pparatus," I desire only to report progress and suggest certain indications for its further trial, that it may reach its proper level among the armamentaria for the treatment of that dreadful malady known under various conditions as phthisis pulmonalis.

Attention has been called before to the inhalation of hot aerial medicaments as a remedy; in I879 I read a paper before the Michigan State Medical Society in which I called attention to a rude apparatus, which I had devised and had been using for some time, to enable patients to inhale a hot balsamic air, with the idea and result of diminishing excessive expectoration. My attention has also been called lately (by Dr. Price Brown of Toronto, Ont.) to cases of individual stokers and molders who have seemed to enjoy comparative immunity from phthisis, notwithstanding strong hereditary and other predisposing causes. The Weigert apparatus, however, is the best and most complete for carrying out such a plan of treatment, and just what its therapeutic value may prove to be is yet a question, for as far as I am able to learn, the highly colored accounts of its successful application do not seem to be borne out here-although perhaps in this country our facilities for experimentation may be meagre, and our conservatism so much greater compared with our old world professional brethren, that their results may not be a fair measure for judgment. It is greatly to be regretted that the apparatus has been patented by a member of the profession, and that the commercial element is so predominating in its introduction to use.

We have been using the Weigert apparatus in Harper Hospital, Detroit, since about March I4, I 889, and, although using it on about twenty patients, more or less, we have only used it in about eight with a constancy and exclusiveness that would serve as a test.

Case 1.-Mrs. S., æt. 39, pneumonic phthisis. Ill since last November; entered the hospital March I6, both lungs involved; right considerably broken down; sputum abounding with myriads of bacilli ; patient very weak and emaciated, with hectic fever and anorexia; able to be out of bed only a short time during the day; temperature range, $97^{\circ}$ to $99^{\circ}$ morning, and ro $2^{\circ}$ to $104^{\circ}$ evening. Began administering hot air inhalation by the Weigert apparatus, of ten to fifteen minutes duration twice daily at a temperature of $100^{\circ}$ to $110^{\circ}$, increasing duration and 
gradually increasing temperature of air to i $20^{\circ}$ the highest which could be borne-was obliged to discontinue on account of the discomfort, in the form of pain in the chest and heat of throat, experienced by patient; no rise of temperature followed, and often easier respiration. Died May 29.

Case 2.-B. O'C., male, æt. 29. Family history bad; hemoptysis eight months before entrance to hospital (March 5); in good flesh, some hectic fever, nocturnal sweating, considerable cough and expectoration, containing a few bacilli, some pus, much emaciated, and weakness growing. Examination showed consolidation with softening spots in upper left lung; pulse range from $90^{\circ}$ to $110^{\circ}$, temperature from $99^{\circ}$ to IOI $^{\circ}$; not much anorexia. Administered hot air twice, three and four times daily for from fifteen to forty minutes, at a temperature ranging from $\mathbf{I} 20^{\circ}$ to 200 , the latter temp. on three occasions only; and $180^{\circ}$ and $190^{\circ}$ on several occasions; the immediate effects were generally good; no untoward signs or sensations following. He left the hospital for the South April I5, improved in every way, since then have not heard from him.

Case 3.-Wm. M., æet. 22. Entered hospital March 7. Been ill with cough, hectic, fever, etc., about six months; habits not good. Consolidation of upper right lung with softening at apex, also consolidated spots in lower right lung; respiration 26 to 30 , pulse ranging from 90 to I I 5 , temperature $99^{\circ}$ to $102^{\circ}$ at times reaching $\mathrm{IO}^{\circ}$, expectoration containing $n o$ bacilli. Began inhalations twice a day for fifteen minutes at a sitting, at temperature of $\mathrm{IIO}^{\circ}$, increasing to three or four times a day of twenty to twenty-five minutes each, with temperature sometimes as high as $195^{\circ}$ on three occasions. Inhalations seemed to cause nausea and vomiting; inhalations always caused increase of temperature and increase of pulse beat from 5 to 15 beats-temperature was raised from $I^{\circ}$ to $3^{\circ}$. April 17 , had hemoptysis; hectic fever diminished in frequency, and when he left the hospital, April I8, was stronger, with less cough and expectoration, and better appetite. $\mathrm{He}$ is away from here now, but, I hear, improving.

Case 4.-Miss K. McD., æt. I9. Entered the hospital March I9. Family history good; been ill two months with cough, expectoration, and severe hectic fever-looked anæmic; felt weak, and had severe nocturnal sweating and suppression of menses. Examination showed some consolidation and mucous râles over both "upper fronts ;" never had hemoptysis, considerable expectoration, bacilli. Pulse range 80 to 100 , temperature range $98^{\circ}$ to $102.5^{\circ}$ from 18 th to 3 Ist. Hot air inhalations from $100^{\circ}$ increasing to $120^{\circ}$, four or five times a day. Discontinued after about ten days, as patient could not stand it, as it caused febrile movement, pain in chest, and breathlessness with nausea. How much was imaginary, cannot say. There was no diminution of bacilli. Is failing.

Case 5.-Miss N. W., æt. 17. Entered the hospital March I5. Healthy, ruddy appearance. Menstruation regular. Been ill one year with cough (on and off) and occasional fever. The illness began with an abscess in axillary glands. No discharge from axilla since November. Two months ago began to have a painful throat, and since one month aphonia. Not much cough or expectoration ; bacilli in sputum ; larynx swollen in arytenoid region and studded with small ulcers. Consolidation of upper left lung, but no râles; "is up" all day; occasional diarrhœa; pulse range 80 to I IO, temperature $97^{\circ}$ to IOI $^{\circ}$; some nocturnal sweating, and considerable diarrhœa at times. Administered inhalations twice and three times daily for about a week when patient could not bear them any longer on account of extreme pain in throat. On account of rapid swelling of larynx had to resort to gavage. Patient left hospital April 26, very weak and emaciated, and died May 24, I889. This was undoubtedly a case of general tuberculosis, with laryngeal disease predominating.

Case 6.-A. M., female, æt. 18. Been ill with cough ten months. Hemoptysis eight months ago, and progressive emaciation, hectic fever, etc., since. Auscultation showed cavities over both upper lungs-more advanced over left. Great expectoration, with bacilli, and diarrhœea very severe at times. Entered hospital April. Pulse range 90 to 130 . Temperature $96.5^{\circ}$ to $104^{\circ}$, from April 24 to May 31. Respiration 26 to 32. Administered hot air twice to three times daily, from ten to twenty-five minutes at a timepatient could no take it longer. A temperature of $110^{\circ}$ to $175^{\circ}$ was the highest that could be borne. She took the inhalation well, and, excepting three times when she felt weak, experienced ease and comfort, with diminution of cough, expectoration, and fever. A severe attack of diarrhœa supervened May 3 and has continued, and she has grown rapidly worse, with œedema of feet, and great debility. Will probably live only a couple of weeks longer.

Case 7.-Miss M. D., æt. 36 . Been ill three years. First ill with pnenmonia. Entered hospital April 27, quite emaciated, weak, but able to be up and about considerably. Considerable cough and expectoration, with myriads of bacilli and pus. Pulse range from IOO to I 20, temperature $99^{\circ}$ to $102^{\circ}$, respirations 22 to 28 . Nocturnal sweating, and chill about every third day-not severe however. Poor appetite, and occasional soreness of throat, and hoarseness. Auscultation showed mucous and gurgling râles all over right lung with loss of vesicular murmur or bronchial respiration, and a large cavity about middle; also mucous râles over "upper left." Hot air inhalations as often as could be borne and as fre- 
quent-averaging three times a day probablywith temperature from $110^{\circ}$ to $140^{\circ}$. The effects were good except that once in a while she felt too feeble to take them. Did not complain of burning or pain, she has gained a little. There has been diminution of moist sounds in lungs, no change in pulse rate or temperature, no more emaciation or loss of strength.

Case 8.-Ait. 26. Entered hospital May 6. Family history good. Contracted an acute pneumonia six years ago since which time has never been well. Has coughed more or less ever since. Was in South (Tennessee) last winter. Never had hemoptysis. Not very much emaciated but has sense of great weakness. Bacilli in sputum. Auscultation showed bronchial respiration over upper and middle lobes of right lung, and bronchophony in patches. Mucous and sibilant râles over both upper fronts. No evidence of cavities. Pulse rate 100 to $\mathrm{I} 20$, temperature $97^{\circ}$ to $104^{\circ}$. Began inhalations of hot air May 7. Averaged three séances daily, of fifteen to twenty-five minutes duration with temperature at $I 10^{\circ}$ to $I 20^{\circ}$ (never could bear them higher than $120^{\circ}$ ). After fourteen days was obliged to stop the hot air on account of exhaustion and loss of appetite apparently produced. Have renewed the inhalations.

I have five cases now under this treatment, in one of which (a very interesting one) improvement seems to follow. We have found it impossible to apply the method for such lengths of time as reported to have been done in Germany; patients would or could not do it. We have found, however, that healthy persons and those with only chronic bronchial catarrh can bear greater heat of air and for a longer time at a sitting than true phthisical cases. We always close the nasal passage during an inhalation.

We shall continue its use for we feel that it has not yet been thoroughly tested either in this country or Europe.

\section{STOMACH REST AND CLEANLINESS.}

Read in the Section of the Practice of Medicine, Materia Medica and l'hysiology, at the Fortieth Annual Meting of the American Medical Association, June, I880.

BY MARY E. BALDWIN, M.D.,

OF NEWPORT, R. I.

Mrs. B. W., aged 52, a widow eight months, came under my observation February $\mathrm{I}_{7}$ of the present year. She was one of five children of good physical parentage, except that the mother had much liver trouble. Mother, one sister and one brother very stout, and one sister has had an immense amount of bilious disturbance for twentyeight years, with suffering so severe as to suggest bilious colic. Came first soon after first delivery. Infancy and childhood were not attended by any serious sickness, and was not in any sense a delicate child, although she had many "worm" at- tacks. Was always fond of candy, cake and sweets. Since first pregnancy, subject to bilious turns with severe attacks of pain, which have usually resisted all home treatment and have been relieved by hypodermics. Although morphine was frequently resorted to, the habit never was formed, and it has not been used the past two years. Since early remembrance has had returns of diarrhœa, but never vomited blood, nor passed it by rectum. Married at I 8 , and soon grew fleshy. Had four children; youngest is $2 \mathrm{I}$. Menopause occurred at 5o, without any special symptoms, and a year later, eight months before first seen, the shock of her tusband's sudden death caused a severe flooding, with no further return. Some fifteen years ago had a tumorprobably urticaria; took medicine for it about five years ago. It disappeared, and patient thinks there has not been a truly well day since that time. Mrs. B. W.'s frame is large and well proportioned; height, 6 feet, and 275 pounds was a usual weight until she began to lose flesh after her husband's death, and the loss continued until the middle of February, when it had fallen to 132. She was a bright, cheerful, and, although so stout, an active woman, until the past five years, at which time she seemed to lose her accustomed vim, often spit up food, and experienced much discomfort from gas in the stomach and bowels. Especially the last two years this train of symptoms grew more marked until the precipitation of actual wretchedness by the shock of bereavement and the exhaustion of a flooding. The eight months previous to the commencement of my knowledge of this case had been attended by the loss of more than half the usual weight. A good appetite stimulated the taking of food, which often came up as soon as swallowed, even causing her to leave the table seven or eight times during a meal. Sometimes food came up sour, again bitter, and usually mixed with a large proportion of slime and phlegm. Never a large amount vomited at one time, and always without retching. Thirst also demanded drink, which gave little relief.

Bowels usually regular, but in January had an evacuation after going four weeks without one. Later went three weeks without any action, and again ten days; each time the attendant suffering was extreme. Urine dark and thick; sometimes could retain, again had to pass frequently. In region of stomach no habitual pain or soreness to touch, but a weary, heavy discomfort and a crowding and distress following food as it went down. Solids and fluids caused equal discomfort, except that hot tea was readily swallowed, but hot water quite certainly induced vomiting. $\mathrm{Pa}$ tient said she could retain ice cream and Valentine's beef with ice, but that milk had not been tolerated in any form. Sometimes distress and gas relieved by soda, and at times ice water stim. 